\title{
Neumonía fatal en una niña inmunocompetente, asociada a herpes simple tipo 1
}

\author{
ADRIANA HENAO L. ${ }^{1}$, OLGA MORALES M. ${ }^{2}$, ANDRÉS CIFUENTES L. ${ }^{3}$, \\ CARLOS GARCÉS S. ${ }^{4}$, MIGUEL ROLDÁN P. ${ }^{5}$ \\ 1. Residente de Pediatría, Dpto. de Pediatría y Puericultura, Universidad de Antioquia, Medellín-Colombia. \\ 2. Pediatra Neumóloga, Departamento de Pediatría y Puericultura, Universidad de Antioquia, Hospital Universitario \\ San Vicente de Paul (HUSVP), Medellín-Colombia. \\ 3. Residente de Pediatría, Departamento de Pediatría y Puericultura Universidad de Antioquia, Medellín-Colombia. \\ 4. Pediatra Infectólogo, Departamento de Pediatría y Puericultura, Universidad de Antioquia, Hospital Universitario \\ San Vicente de Paul (HUSVP). Medellín-Colombia. \\ 5. Patólogo, Departamento de Patología, Hospital Universitario San Vicente de Paul (HUSVP). Universidad de Antioquia, \\ Medellín-Colombia.
}

\begin{abstract}
Fatal pneumonia associated to herpes simplex 1, in an immunocompetent girl

Most reported cases of lower respiratory tract infection due to herpes simplex virus type-1 (HSV-1) occurs in immunocompromised patients, however there are few cases of viral infection in inmunocompentes critically ill patients (1-3). Objective: Report the case of fatal VHS-1 pneumonia in an immunocompetent patient. Case: A ten year old girl, immunocompetent, who presents respiratory symptoms and progresses rapidly to severe hypoxemia, instability and death. Lung biopsy reported Cowdry type A inclusions and the polimerasa chain reaction (PCR) was positive for HSV-1. We discuss the clinical features, diagnosis, treatment and prognosis in critically ill immunocompetent patients with HSV-1 infection in lower respiratory tract.
\end{abstract}

(Key words: Pneumonia, fatal, herpes simple type 1).

Rev Chil Pediatr 2011; 82 (4): 329-335

\section{RESUMEN}

La mayoría de los casos reportados de infección por el virus herpes simplex tipo-1 (VHS-1) en el tracto respiratorio inferior ocurren en pacientes inmunosuprimidos; sin embargo, se han reportado casos de aislamiento del virus en pacientes inmunocompentes en estado crítico. Objetivo: Reportar el caso de neumonía grave y fatal por VHS-1 en un paciente inmunocompetente. Caso Clínico: Paciente de 10 años, sexo femenino, inmunocompetente, que inicia síntomas respiratorios y progresa rápidamente a hipoxemia severa, inestabilidad y

Trabajo recibido el 03 de febrero de 2011, devuelto para corregir el 21 de abril de 2011, segunda versión el 02 de mayo de 2011, tercera versión el 25 de mayo de 2011, aceptado para publicación el 21 de junio de 2011.

Correspondencia a:

Dra. Adriana Henao L.

E-mail: adrisahenao@yahoo.com 
muerte. La biopsia pulmonar reportó inclusiones de Cowdry tipo A y una reacción en cadena de la polimerasa (PCR) positiva para VHS-1. Discusión: Se comenta el cuadro clínico, diagnóstico, tratamiento y pronóstico en pacientes inmunocompetentes críticamente enfermos con infección por VHS-1 en el tracto respiratorio inferior (Palabras clave: Neumonia, fatal, virus herpes simple tipo 1).

Rev Chil Pediatr 2011; 82 (4): 329-335

\section{Introducción}

Entre 2 y 3\% de la población sana puede tener VHS-1 en el tracto respiratorio superior, sin presencia de manifestaciones clínicas ${ }^{4}$. En algunos pacientes críticamente enfermos con compromiso pulmonar, se ha aislado del tracto respiratorio superior e inferior ${ }^{5}$. Muchos de los casos descritos en pacientes sin antecedente de inmunosupresión están asociados a ventilación mecánica prolongada con una alta mortalidad $^{1-3}$. No es claro si el aislamiento en el tracto respiratorio inferior de estos pacientes corresponde a una contaminación, una reactivación por su estado crítico o porque realmente corresponde a la etiología del cuadro clíni$\mathrm{Co}^{6,7}$. No obstante, sí se ha encontrado que su presencia se asocia con un peor pronóstico ${ }^{4,6-8}$. Algunos de los factores de riesgo encontrados para neumonía por VHS-1 en los pacientes con ventilación mecánica por más de 5 días, fueron la presencia de lesiones oro-labiales, el hallazgo de el virus en la garganta y las lesiones vistas durante la broncoscopía ${ }^{1}$. La infección del tracto respiratorio inferior por el VHS-1 descrita en pacientes inmunocompetentes intubados en unidades de cuidado intensivo (UCI) se relaciona con fiebre persistente e infiltrados pulmonares acompañados de hipoxemia severa debido a una profunda alteración en la difusión de oxígeno con una "falla en el destete del ventilador”. El diagnóstico de la infección se realiza luego de tomar un estudio histológico, donde se identifican los cambios citopáticos en el epitelio respiratorio bronquial distal, que indican la invasión de tejidos ${ }^{9}$.

El objetivo de esta publicación es presentar el caso clínico de una niña previamente sana, con un cuadro clínico de neumonía grave, falla ventilatoria y muerte, asociada a la infección con VHS-1 en el tracto respiratorio inferior. Se discuten, la patogenia, el diagnóstico, el tratamiento y pronóstico de esta asociación.

\section{Caso clínico}

Paciente de sexo femenino, 10 años de edad, residente en área urbana, de raza blanca, previamente sana y sin antecedente de viajes recientes, ni mascotas. Presentó, durante el mes de diciembre un cuadro de 2 días de evolución de tos seca, fiebre objetiva $\left(40^{\circ} \mathrm{C}\right)$, cefalea, epistaxis y mialgias. Consultó ambulatoriamente y recibió tratamiento con amoxacilina y acetaminofeno durante 7 días, sin mejoría de la sintomatología. Consultó nuevamente a un hospital de alta complejidad, por aumento de la dificultad respiratoria, donde encontraron a la paciente en regulares condiciones generales, con dificultad respiratoria, presión arterial 100/70 mmHg, frecuencia cardíaca de 100/minuto, temperatura de $39^{\circ} \mathrm{C}$, saturación de oxígeno $\left(\mathrm{SO}_{2}\right)$ 91\% con $\mathrm{FIO}_{2}$ de $40 \%$, mucosas pálidas, ruidos cardíacos rítmicos, taquicárdicos, sin soplos; hipoventilación basal izquierda asociada a soplo tubárico, crépitos y pectoriloquia; hepatomegalia de $4 \mathrm{~cm}$ por debajo del reborde costal derecho; sin otros hallazgos de enfermedad pulmonar crónica. La radiografía de tórax mostró opacidad de tipo relleno alveolar en región retrocardíaca izquierda (figura 1). Se hospitalizó con diagnóstico de neumonía adquirida en la comunidad y se inició tratamiento con oxígeno suplementario y piperazilina tazobactam. Los exámenes de laboratorio iniciales mostraron hemoglobina de 7,5 g/dl, hematocrito 22,4\%, leucocitos $1300 /$ $\mathrm{mm}^{3}$, PMN 37\% (450), linfocitos 48\% (624/ $\mathrm{mm} 3$ ), PCR de 2,51 mg/dl, plaquetas 400 000/ $\mathrm{mm}^{3}$, función renal normal, ionograma normal y leve aumento de las transaminasas. 


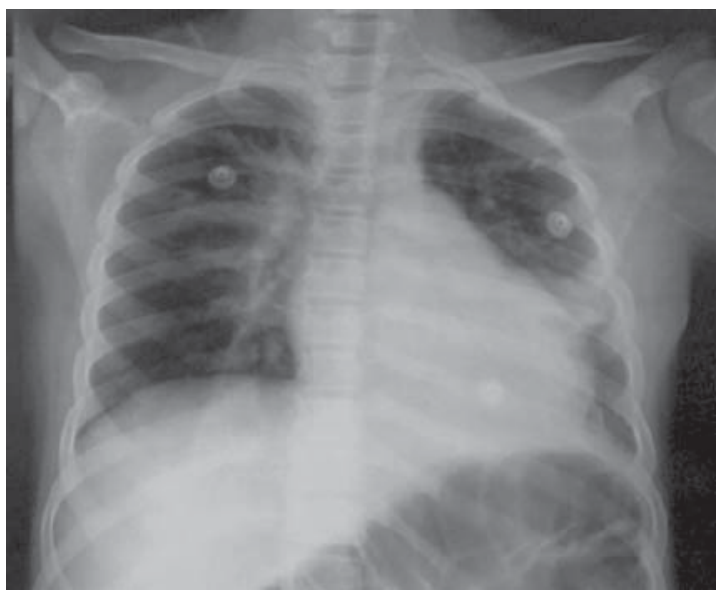

Figura 1. Radiografía de tórax AP, con extensa imagen de relleno alveolar en región retrocardíaca izquierda

Durante los primeros 2 días de hospitalización continuó febril y con aumento en los requerimientos de oxígeno e hipotensión. Se trasladó a la unidad de cuidados intensivos pediátricos (UCIP), donde iniciaron tratamiento antibiótico empírico con ceftriaxona, oxacilina, vancomicina y oxígeno suplementario con máscara de no reinhalación para saturaciones mayores de 90\%. El mismo día del ingreso a UCIP presentó deterioro clínico, somnolencia, hipoxemia severa, hipotensión y signos de disfunción miocárdica; se consideró que la paciente tenía choque séptico, freno medular y falla ventilatoria secundaria a neumonía severa. Se inició soporte ventilatorio, inotrópico y al siguiente día se amplió el espectro antibiótico a: meropenem, trimetropim sulfa, claritomicina y oseltamivir (tabla 1). Evolución con inestabilidad hemodinámica y requerimientos de altos parámetros ventilatorios. A las 36 horas del ingreso a UCIP se evidenció compromiso bilateral en la radiografía de tórax (figura 2) y evolución a síndrome de distress respiratorio del adulto (SDRA). Los exámenes de laboratorio de control mostraron mejoría de la leucopenia, persistencia de la linfopenia y sin trombocitopenia.

La biopsia pulmonar y el lavado broncoalveolar (LBA) eran indispensables para determinar la etiología del cuadro clínico, sin embargo, las condiciones de la paciente, los altos parámetros ventilatorios y la labilidad hemo-

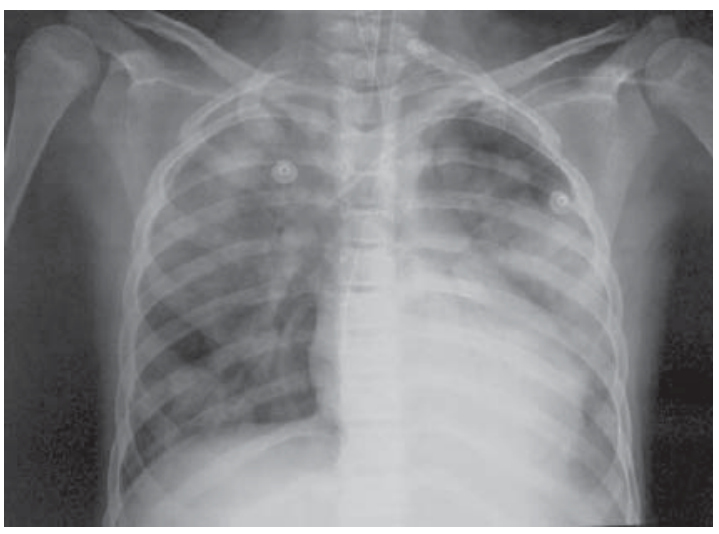

Figura 2. Radiografía de tórax que evidencia mayor extensión de la opacidad de tipo relleno alveolar, abarcando casi todo el campo pulmonar izquierdo e infiltrados intersticiales difusos bilaterales, con corazón de tamaño adecuado.

Tabla 1. Inicio y suspensión de los antibióticos

\begin{tabular}{|ll|}
\hline Evolución & Antibiótico \\
\hline Inicio de los síntomas & Amoxacilina oral durante 7 días \\
\hline Ingreso al hospital & Piperacilina tazobactam \\
\hline $\begin{array}{l}\text { A los } 2 \text { días del } \\
\text { ingreso }\end{array}$ & $\begin{array}{l}\text { Suspensión de piperacilina tazo- } \\
\text { bactam } \\
\text { Inicio de ceftriaxona, vancomicina } \\
\text { y oxacilina }\end{array}$ \\
\hline Al 3 día & $\begin{array}{l}\text { Suspensión de ceftriaxona y oxacilina } \\
\text { Inicio de meropenem, trimetropim } \\
\text { sulfa, claritomicina y oseltamivir }\end{array}$ \\
\hline A los 14 días & $\begin{array}{l}\text { Suspensión de meropenem, trime- } \\
\text { tropim sulfa, claritomicina }\end{array}$ \\
\hline A los 21 días & $\begin{array}{l}\text { Inicio de cefepime y linezolid } \\
\text { Suspensión de cefepime y linezolid }\end{array}$ \\
\hline
\end{tabular}

dinámica, hacían estos procedimientos de alto riesgo y los padres no lo aceptaron. Por lo cual sólo fue posible tomar cultivo de secreción traqueal (tabla 2).

Dos semanas más tarde requirió toracostomia bilateral, por la presencia de neumotórax, neumomediastino y neumopericardio. Presentó posteriormente hipoxemia refractaria $\left(\mathrm{SO}_{2}\right.$ 72 a 82\%), persistencia de la fiebre y episodios de taquicardia supraventricular multifactorial manejados farmacológicamente y con cardioversión. Se sospechó neumonía asociada al ventilador y se inició cefepime y linezolid (tabla 1). Se tomó además una tomografía computada de alta resolución (TCAR) de tórax 
Tabla 2. Estudios para determinar agente etiológico

\begin{tabular}{|c|c|c|}
\hline Estudios & Examen & Resultado \\
\hline \multirow[t]{6}{*}{$\begin{array}{l}\text { A los } 2 \text { días del in- } \\
\text { greso hospitalario }\end{array}$} & $\begin{array}{l}\text { Panel respiratorio viral (inmunofluorescencia indirec- } \\
\text { ta) para adenovirus, parainfluenza, influenza y virus } \\
\text { respiratorio sincicial }\end{array}$ & Negativo \\
\hline & IgM para Mycoplasma pneumoniae & Negativo \\
\hline & IgG, IgM y carga viral para citomegalovirus & Negativos \\
\hline & IgM para virus de Epstein Barr & Negativo \\
\hline & Elisa para virus de inmunodeficiencia humana $(\mathrm{VIH})$ & Negativo \\
\hline & $\begin{array}{l}\text { Baciloscopias y cultivos para seriados Mycobacterium } \\
\text { tuberculosis de jugo gástrico número } 3\end{array}$ & Negativos \\
\hline A los 3 días & PCR para Influenza A H1N1 & Negativa \\
\hline $\begin{array}{l}\text { A los } 4 \text { días del in- } \\
\text { greso hospitalario }\end{array}$ & El cultivo de la secreción traqueal & $\begin{array}{l}\text { Negativo para bacterias, hongos y Mycobacterium } \\
\text { tuberculosis }\end{array}$ \\
\hline $\begin{array}{l}\text { A los } 8 \text { días del in- } \\
\text { greso hospitalario }\end{array}$ & Aspirado de médula ósea & $\begin{array}{l}\text { Normocelularidad con la serie granulocitica en todos } \\
\text { los estadios y cambios megaloblásticos, los cultivos } \\
\text { para bacterias, hongos y Mycobacterium tuberculosis } \\
\text { fueron negativos. Las tinciones especiales (gram, plata } \\
\text { metanamina y Zihel-Neelsen) fueron negativas }\end{array}$ \\
\hline A los 34 días & Biopsia pulmonar & $\begin{array}{l}\text { Cultivo para bacterias, hongos y Mycobacterium } \\
\text { tuberculosis negativos, las tinciones especiales (gram, } \\
\text { plata metanamina, Gracot y Zihel-Neelsen) fueron } \\
\text { negativas. PCR para citomegalovirus, virus de Epstein } \\
\text { Barr negativas }\end{array}$ \\
\hline
\end{tabular}

(figura 3), que reveló áreas de vidrio esmerilado, con neumotórax bilateral (a pesar de los tubos a tórax), con áreas de atelectasia pasiva y posible fibrosis en las bases, con corazón de tamaño normal.

A los 34 días, luego del ingreso hospitalario, se llevó a traqueostomia y biopsia pulmonar la cual reportó cuboidización de los alvéolos (figura 4), inclusiones de Cowdry tipo A (inclusiones eosinofílicas intranucleares rodeadas de un halo claro); la PCR en tiempo real cualitativa fue positiva para VHS-1 (figura 5).

Durante la estancia hospitalaria se realizaron exámenes para tratar de identificar la etiología del cuadro clínico, que incluyeron 2 tomas simultáneas de hemocultivos en 3 oportunidades y resultaron todas negativas, y 3 urocultivos negativos (tabla 2).

Se tomaron niveles de inmunoglobulinas séricas evidenciándose una hipogamaglobulinemia a expensas de la IgG 510 mg/dl (VR 833-2 399), los controles posteriores mostraron tendencia a la mejoría (IgG $796 \mathrm{mg} / \mathrm{dl}$ ); sin embargo, se mantuvo por debajo del límite inferior para la edad. Se consideró una hipogamaglobulinemia del paciente en estado crítico, por lo que recibió una dosis de gamaglobulina intravenoso. Por la linfopenia se solicitó una subpoblación de linfocitos, la cual a pesar de estar disminuida conservaba las proporciones adecuadas de CD4, CD3 y CD8. La ecocardiografía reportó hipertensión pulmonar leve.

La paciente permaneció en ventilación mecánica con parámetros altos por 38 días, con posterior disfunción miocárdica e hipoxemia persistente que la llevaron a la muerte. El estudio histopatológico completo de la biopsia pulmonar se reportó al día siguiente de su fallecimiento, por lo cual no recibió tratamiento para el VHS-1.

\section{Discusión}

La infección por VHS-1 se presenta frecuentemente en pacientes inmunosuprimidos, incluyendo, quemaduras severas, quimioterapia y trasplante de órgano ${ }^{10,11}$.

Desde hace varios años se han reportando 


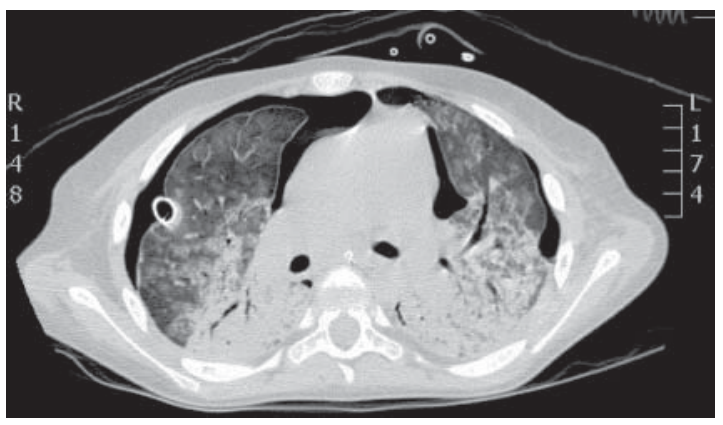

Figura 3. TCAR de tórax evidencia áreas de vidrio esmerilado, atelectasias pasivas posteriores, neumotórax bilateral y corazón de tamaño normal.

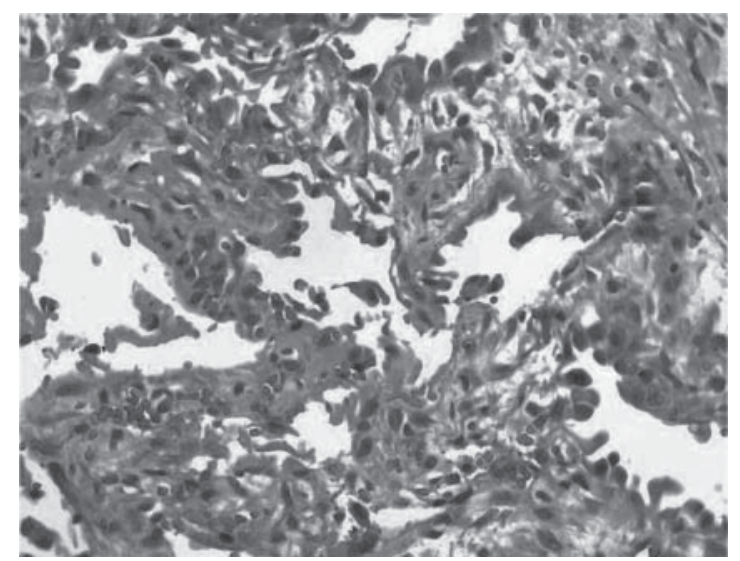

Figura 4. Biopsia pulmonar con marcada cuboidización de los alvéolos.

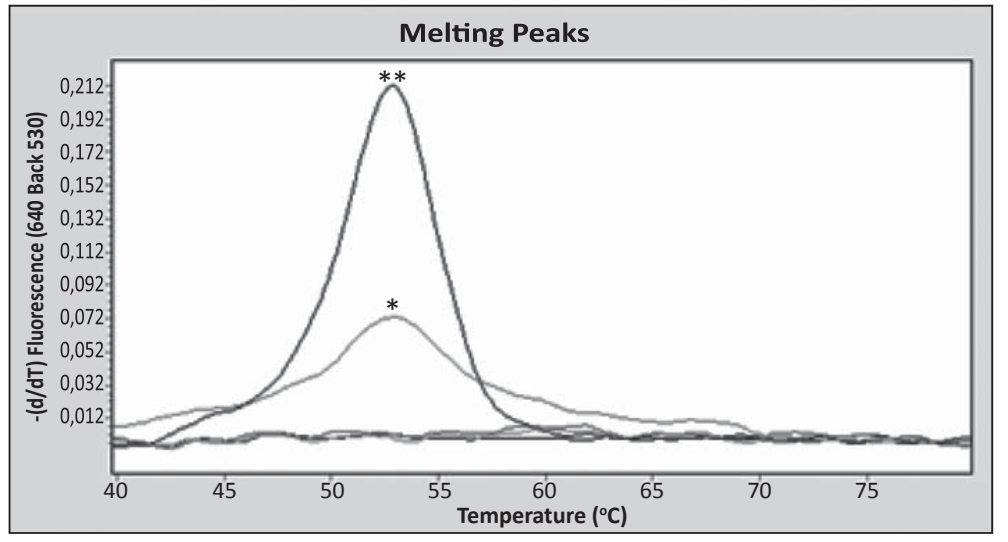

Figura 5. PRC tiempo real: curva * corresponde a control positivo para VHS1 , curva ** corresponde a resultado de la paciente. casos de aislamiento de VHS-1 en biopsias pulmonares de pacientes que fallecen con diagnóstico de neumonía grave de causa desconocida ingresados a UCI, lo cual podría indicar que este virus es el agente causal o una reactivación en el paciente crítico $^{12}$. No es claro aún si la presencia del VHS-1 tiene un papel importante en la patogenia o en la evolución clínica de estos pacientes. En un estudio prospectivo de pacientes en una unidad de cuidados intensivos, se encontró una alta prevalencia del VHS-1 en el tracto respiratorio superior, lo cual fue un factor de riesgo para encontrarlo en el tracto respiratorio inferior; el virus se identificó principalmente en pacientes con compromiso severo y se relacionó a una estancia hospitalaria prolongada ${ }^{13}$. Así mismo, un estudio retrospectivo que evalúo pacientes críticamente enfermos en UCI, reportó que fallecieron el $40 \%$ de aquellos en quienes se aisló el VHS-1 en el LBA, principalmente debido a una enfermedad subyacente grave y la comorbilidad, lo cual pueden predisponer a la reactivación endógena del virus ${ }^{14}$.

En un reporte de caso, la infección VHS1 en el tracto respiratorio inferior de un joven inmunocompetente, se localizó principalmente en la tráquea y en los bronquios; observándose a través de la broncoscopia, úlceras difusas o focales con depósitos de exudados de fibrina ${ }^{15}$. En nuestro reporte, el lavado broncoalveolar y la biopsia se tomaron tardíamente, debido a la inestabilidad hemodinámica y a la negativa de los padres; en ella no se reportaron lesiones en la tráquea ni bronquios.

Los microorganismos que se han asociado a hipoxemia severa y progresión a SDRA son el virus sincicial respiratorio, el influenza 
A H1N1 pandémica, Pneumocystis jirovecii, VHS-1, virus del herpes simplex tipo 6, virus de Epstein Barr, virus influenza A H5N1, Chlamydia pneumoniae y metaneumovirus humano, entre otros ${ }^{16-19}$. El diagnóstico de trabajo del caso reportado, fue una neumonía grave con hipoxemia severa y progresión a SDRA; aunque los estudios microbiológicos y serológicos fueron negativos para detectar el agente etiológico, la prescripción de los antibióticos empíricos obedeció probablemente a la rápida progresión y severidad del cuadro clínico, la no detección del agente etiológico y la pobre respuesta, en las primeras 24 a 48 horas, de los tratamientos instaurados. El perfil de medicamentos intentaba cubrir posibles agentes etiológicos, como bacterias atípicas, Staphylococcus aureus sensible a meticilina y resistente a meticilina, Pneumocystis jirovecii, el virus influenza A H1N1; sin embargo, no se inició manejo empírico con aciclovir.

El diagnóstico de infección por VHS-1 en el tracto respiratorio inferior se realiza en base a los datos citológicos e histológicos y se confirma con el aislamiento del virus por medio del cultivo, la detección de antígenos o por la PCR en LBA o biopsia de tejido pulmonar. La biopsia del parénquima pulmonar muestra típicamente nódulos o focos confluentes de necrosis e histológicamente son características las inclusiones de Cowdry tipo A (inclusiones eosinofílicas intranucleares rodeadas de un halo claro). En este caso los hallazgos histológicos y los valores de la PCR encontrados en el parénquima pulmonar fueron compatibles con la infección por el VHS-1 en el tracto respiratorio inferior. El laboratorio de referencia donde se realizó la PCR cualitativa en tiempo real, encontró niveles muy elevados. La PCR es una prueba muy sensible que se utiliza para detectar la presencia de ADN viral en muestras de LBA y biopsias pulmonares. Valores superiores a 105 copias/ml del VHS-1 en el LBA de los pacientes en UCI, se han asociado con peor pronóstico y alta mortalidad ${ }^{8}$.

El seguimiento de la carga viral en muestras consecutivas de los pacientes intubados con PCR positiva reveló un patrón de cinética típica, donde inicialmente se reportó una carga viral $>103$ copias/ml y 7 días después de la intubación se presentó un aumento exponencial de la carga viral por 1,17 $(0,95$ a 1,37) log copias/ml por día, alcanzando una concentración máxima después de una mediana de 12 días de intubación; relacionándose a mayor morbilidad y estancias prolongadas en la UCI. Lo anterior indica que la carga viral puede dar una idea de la magnitud de la reactivación viral y del impacto clínico ${ }^{4}$. En esta paciente la PCR se realizó a los 32 días postintubación orotraqueal, con resultados positivos, muy por encima del límite superior, lo cual plantea el interrogante de si, en este caso, se trató de una paciente critica con falla ventilatorio secundaria posiblemente a una infección de etiología desconocida, asociada a una reactivación del VHS-1 que exacerbó su cuadro clínico; o si fue el VHS-1 la causa desde el comienzo.

La paciente no tenía antecedente de inmunosupresión por lo que la hipogamaglobulinemia descrita y el freno medular iniciales, se interpretaron como hallazgos secundarios a la infección severa; se han reportado casos de hipogamaglobulinemia secundaria a infección viral $^{20,21}$.

El tratamiento con aciclovir o vidarabina, sumando al soporte ventilatorio, es recomendado en estos pacientes. Cuando se inicia tempranamente puede mejorar la sobrevida y disminuir el período de la enfermedad ${ }^{15}$

La importancia de este caso es sospechar la asociación del VHS-1 en pacientes críticos, con ventilación mecánica prolongada y sin respuesta a los tratamientos instaurados, teniendo en cuenta que el tratamiento de la infección o la coinfección por el VHS-1 podría mejorar el pronóstico de estos pacientes.

\section{Referencias}

1.- Luyt CE, Combes A, Deback C, et al: Herpes simplex virus lung infection in patients undergoing prolonged mechanical ventilation. Am J Respir Crit Care Med 2007; 175 (9): 935-42.

2.- Schuller D, Spessert C, Fraser VJ, Goodenberger DM: Herpes simplex virus from respiratory tract secretions: epidemiology, clinical characteristics, and outcome in immunocompromised and nonimmunocompromised hosts. Am J Med 1993; 94 (1): 29-33. 
3.- Schuller D: Lower respiratory tract reactivation of herpes simplex virus Comparison of immunocompromised and immunocompetent hosts. Chest 1994; 106(1 Suppl): 3S-7S.

4.- McMillan JA, Weiner LB, Higgins AM, Lamparella VJ: Pharyngitis associated with herpes simplex virus in college students. Pediatr Infect Dis 1993; 12 (4): 280-4.

5.- De Vos N, Van Hoovels L, Vankeerberghen A, et al: Monitoring of herpes simplex virus in the lower respiratory tract of critically ill patients using real-time PCR: a prospective study. Clin Microbiol Infect 2009; 15 (4): 358-63.

6.- Tuxen DV, Cade JF, McDonald MI, Buchanan MR, Clark RJ, Pain MC: Herpes simplex virus from the lower respiratory tract in adult respiratory distress syndrome. Am Rev Respir Dis 1982; 126 (3): 416-9.

7.- Ong GM, Lowry K, Mahajan S, et al: Herpes simplex type 1 shedding is associated with reduced hospital survival in patients receiving assisted ventilation in a tertiary referral intensive care unit. J Med Virol 2004; 72 (1): 121-5.

8.- $\quad$ Linssen CFM, Jacobs JA, Stelma FF, et al: Herpes simplex virus load in bronchoalveolar lavage fluid is related to poor outcome in critically ill patients. Intensive Care Med 2008; 34: 2202.

9.- Mohan S, Hamid NS, Cunha BA: A cluster of nosocomial herpes simplex Virus type 1 pneumonia in a medical intensive care unit. Infect Control Hosp Epidemiol 2006; 27 (11): 1255-7.

10.- Aquino SL, Dunagan DP, Chiles C, Haponik EF: Herpes simplex virus pneumonia: patterns on CT scans and conventional chest radiographs. J Comput Assist Tomogr 1998; 22 (5): 795-800.

11.- Simoons-Smit AM, Kraan EM, Beishuizen A, Strack van Schijndel RJ, Vandenbroucke-Grauls CM: Herpes simplex virus type 1 and respiratory disease in critically-ill patients: Real pathogen or innocent bystander?. Clin
Microbiol Infect 2006; 12 (11): 1050-9.

12.- Miyazato A, Kishimoto H, Tamaki K, Nakama K, Saito $A$ : Herpes simplex virus bronchopneumonia in a nonimmunocompromized individual. Intern Med 2001; 40 (8): 836-40.

13.- Bruynseels P, Jorens PG, Demey HE, et al: Herpes simplex virus in the respiratory tract of critical care patients: a prospective study. Lancet 2003; 362 (9395): 1536-41.

14.- Van den Brink JW, Simoons-Smit AM, Beishuizen A, Girbes AR, Strack Van Schijndel RJ, Groeneveld AB: Respiratory herpes simplex virus type 1 infection/colonisation in the critically ill: marker or mediator?. J Clin Virol 2004; 30 (1): 68-72.

15.- Martínez E, de Diego A, Paradis A, Perpiñá M, Hernández $M$ : Herpes simplex pneumonia in a young immunocompetent man. Eur Respir J 1994; 7: 1185-8.

16.- Merk J, Schmid FX, Fleck M, et al: Fatal pulmonary failure attributable to viral pneumonia with human herpes virus 6 (HHV6) in a young immunocompetent woman. J Intensive Care Med 2005; 20 (5): 302-6.

17.- Riachy M, Baaklini C, Ibrahim I, et al: Acute respiratory distress syndrome complicating Ebstein-Barr virus pneumonia. Rev Mal Respir 2007; 24 (5): 639-43.

18.- Drosten C. Günther S, Preiser W, et al: Identification of a novel coronavirus in patients with severe acute respiratory syndrome. N Engl J Med 2003; 348: 1967-76.

19.- Bauer TT, Ewig S, Rodloff AC, Muller EE: Acute respiratory distress syndrome and pneumonia: a comprehensive review of clinical data. Clin Infect Dis 2006; 43 (6): 748-56.

20.- Oberholzer A, Oberholzer C, Moldawer LL: Sepsis syndrome: understanding the role of innate and acquired immunity. Shock 2001; 16: 83-96.

20.- Jaffe E, Lejtenyi M, Noya F, Mazer B: Secundary hypogammaglobulinemia. Immunology and Allergy Clinics of North America 2001; 21 (1): 1:22. 